\title{
Orbito-Frontal Cortex Volumes in Panic Disorder
}

\author{
Murad Atmaca $^{1 凶}$, Hanefi Yildirim², M. Gurkan Gurok and Muammer Akyol ${ }^{2}$ \\ 'Department of Psychiatry, Firat University School of Medicine, Elazig, Turkey \\ ${ }^{2}$ Department of Radiology, Firat University School of Medicine, Elazig, Turkey
}

\begin{abstract}
Objective Given the association between the pathophysiology of panic disorder and prefrontal cortex function, we aimed to perform a volumetric MRI study in patients with panic disorder and healthy controls focusing on the in vivo neuroanatomy of the OFC.

Methods Twenty right-handed patients with panic disorder and 20 right-handed healthy control subjects were studied. The volumes of whole brain, total white and gray matters, and OFC were measured by using T1-weighted coronal MRI images, with 1.5 -mm-thick slices, at 1.5T. In addition, for psychological valuation, Hamilton Depression Rating (HDRS) and Panic Agoraphobia Scales (PAS) were administered.

Results Unadjusted mean volumes of the whole brain volume, total white and gray matter were not different between the patients and healthy controls while the patient group had significantly smaller left $(t=-6.70, p<0.0001)$ and right $(t=-5.86, p<0.0001)$ OFC volumes compared with healthy controls.

Conclusion Our findings indicate an alteration of OFC morphology in the panic disorder and suggest that OFC abnormalities may be involved in the pathophysiology of panic disorder.

Psychiatry Investig 2012;9:408-412
\end{abstract}

Key Words Panic disorder, Volume, OFC, MRI.

\section{INTRODUCTION}

Panic disorder, as defined by the Diagnostic and Statistical Manual of Mental Disorders, 4th ed. (DSM-IV), is a severe psychiatric disorder associated with significant impairment of the patients' quality of life as well as their social life function. ${ }^{1}$ It affects 2.7 percent of the general population at some point in their lives. ${ }^{2}$ It is a chronic and often disabling anxiety disorder. Panic disorder is characterized by unexpected panic attacks. $^{2}$

Functional studies revealed that extensive cerebrocortical regions, especially the prefrontal cortex, limbic structures and temporal cortex could be related to the pathophysiology of panic disorder. Firstly, Fischer et al. ${ }^{3}$ who used positron emission tomography (PET) demonstrated decreased regional ce-

Received: September 30, 2011 Revised: January 22, 2012

Accepted: March 26, 2012 Available online: November 12, 2012

$\triangle$ Correspondence: Murad Atmaca, MD

Firat (Euphrates) Universitesi, Firat Tip Merkezi, Psikiyatri Anabilim Dali, 23119 Elazig, Turkey

Tel: +90-424-233-3555/2965, Fax: +90-424-238-7688

E-mail: matmaca_p@yahoo.com

(a) This is an Open Access article distributed under the terms of the Creative Commons Attribution Non-Commercial License (http://creativecommons.org/licenses/bync/3.0) which permits unrestricted non-commercial use, distribution, and reproduction in any medium, provided the original work is properly cited. rebral blood flow ( $\mathrm{rCBF}$ ) in the right orbitofrontal cortex (OFC), anterior cingulate cortex (ACC), and anterior temporal cortex in a patient who unexpectedly experienced a panic attack. Coplan and Lydiard ${ }^{4}$ suggested that dysfunction of the prefrontal cortex and excessive activation of the limbic structures including amygdala, could play an important role in panic disorder. In other studies, 5,6 it was demonstrated a relationship between activation in the amygdala and cingulate cortex and fearful-neutral face recognition in patients with panic disorder, and cerebellar vermis, temporal pole, insular cortex and thalamus activation in panic attacks induced in healthy subjects by injecting them with cholecystokinin tetrapeptide (CCK-4), respectively. Gorman et al. ${ }^{7}$ reported that several other regions such as the hippocampus, thalamus, insular cortex and cingulate cortex, in addition to the amygdala and prefrontal cortex, also contributed to the pathogenesis of panic disorder.

As for the structural neuroimaging investigations, there have been limited studies. In majority of these studies, volumes reductions were reported in the amygdala, parahippocampus, putamen, temporal lobe and right inferior frontal gyrus, left superior frontal gyrus and left superior temporal gyrus (STG). ${ }^{8-13}$ In addition, insignificant volume increase of the brainstem, and no change in the hippocampus were also 
reported. ${ }^{11,14}$ Asami et al. ${ }^{15}$ found significant gray matter volume reductions of the bilateral dorsomedial and right ventromedial prefrontal cortices, right amygdala, anterior cingulate cortex, bilateral insular cortex, occipitotemporal gyrus and left cerebellar vermis in the patients with panic disorder compared to controls. In these studies, prefrontal cortex seems one of the important regions in the neuroanatomy of panic disorder. However, Uchida et al. ${ }^{16}$ did not report any gray matter abnormality of the prefrontal cortex in the patients with panic disorder. In our a previous investigation on obsessive compulsive disorder (OCD), ${ }^{17}$ we found that OCD group had significantly smaller left and right OFC volumes and significantly greater left and right thalamus volumes compared to healthy controls whereas anterior cingulate exhibited a near-significant difference between the patients and healthy controls on left side. In our another study, ${ }^{18}$ we suggested that reductions in OFC and increase in thalamus volumes might be associated with refractoriness of OCD. It is established that OFC seems one of most important key brain regions in the neuroanatomy of OCD. OFC receives direct reciprocal connections from the amygdala ${ }^{19}$ which is an important region in the neuroanatomical pathways for panic disorder. So they may be working together to mediate anxiety. It has been demonstrated that OFC mediates anxiety behavior and perception in child and adolescent primates ${ }^{20}$ and is involved in emotional processing ${ }^{21}$ as much the most important clinical aspect of panic disorder, anxiety and fear are associated with the function of the amygdala and fear sensation is stored in the hippocampus itself.

On the other hand, comorbidity studies revealed an important association between panic disorder and OCD, but little is known about the real relationship. ${ }^{22-29}$ Given the association between panic disoder and prefrontal cortex, and between panic disorder and OCD, we aimed to perform a volumetric MRI study in the patients with panic disorder and healthy controls patients focusing on the in vivo neuroanatomy of the whole brain, total gray and white matter volume, and OFC.

\section{METHODS}

\section{Subjects and clinical evaluations}

The study group was composed of twenty patients with panic disorder without agoraphobia (12 females and 8 males) who were recruited from Firat University School of Medicine Department of Psychiatry. Diagnoses were made according to the Diagnostic and Statistical Manual of Mental Disorders Fourth Edition (DSM-IV) and the Structured Clinical Interview for the Diagnostic Schedule for Mental DisordersFourth Edition (SCID).$^{30}$ Severity of panic symptoms was assessed by using the Panic Agoraphobia Scale (PAS). ${ }^{31}$ On the other hand, severity of depressive symptoms was assessed by using the Hamilton Depression Rating Scale (HDRS). ${ }^{32}$ Their age, sex and parental socio-economic status (SES) were matched by 20 healthy control subjects recruited from the community and hospital staff.

The exclusion criteria included followings: any current comorbid psychiatric disorders except depressive disorder, current or lifetime neurologic diseases, current medical problems, history of head trauma, and alcohol/substance abuse within the 6 months preceding the study. With respect to comorbidity in the patient group, as assessed by the SCID and clinical interviews, two patients met criteria for major depressive disorder. Additional comorbid lifetime Axis I psychiatric diagnoses were social anxiety disorder $(n=2)$, hypochondriasis $(n=1)$, and obsessive compulsive disorder $(n=1)$. They had history of following pharmacological treatment for these comorbidities: Paroxetine in three patients, clomipramine in two patients, sertraline in one patient, haloperidole in one patient. Healthy control subjects had no DSM-IV Axis I disorders in self or in a first-degree relative, beyond thay had no current medical problems, neurologic or psychiatric histories, and no use of psychoactive medication. They were comparable in regard to education level, as mentioned also in the Results section.

The procedures followed were in accordance with the Helsinki Declaration of 1975, as revised in 1983.

\section{MRI procedure}

MRI were acquired with a 1.5-Tesla GE signa Excite high speed scanner (Milwakuee, USA). A high-resolution structural image of the entire brain was obtained using sagittally acquired 3D spiral fast spin echo high-resolution images [repetition time $(\mathrm{TR})=2,000 \mathrm{~ms}$, echo time $(\mathrm{TE})=15.6 \mathrm{~ms}$, field of view $(\mathrm{FOV})=240 \mathrm{~mm}$, flip angle $=20^{\circ}$, bandwidth $=$ 20.8 , slice thickness $=2.4 \mathrm{~mm}$, echo spacing $=15.6 \mathrm{~ms}, 8$ echoes, matrix size $=240$, resolution $=0.9375 \times 0.9375 \times 2.4 \mathrm{~mm}]$.

Anatomic measurements were obtained on a computer advanced workstation with the GE Volume Viewer voxtool 4.2 program. Tracing was performed by one researcher (HY) blind to subject diagnosis. Measured brain structures consisted of the whole brain, total gray and white matter volumes, and OFC. The boundaries of structures evaluated were delineated on the coronal MR images according to standard brain atlases ${ }^{33-35}$ and were adapted from Riffkin et al. ${ }^{36}$ For the tracing procedure for measuring the OFC, superior boundary was defined by a line extending from the anterior commissure to the posterior commissure. On the coronally, the posterior boundary was defined as the point when the olfactory sulcus was first noticed. The inferior boundary was accepted as the most inferior aspect of the cortex. The lateral and me- 
dial boundaries were defined as the most lateral edge of the cortex and the medial boundary of each hemisphere by the longitudinal fissure, respectively. Example of the structure of coronal slices is presented in Figure 1. All volumes were reported in cubic centimeters. The intrarater reliability was enough, with a intraclass correlation coefficient of 0.88 for OFC.

\section{Statistical analysis}

Analysis of covariance (ANCOVA), t test and partial correlation analyses were conducted using SPSS for Windows software, version 13.0 (SPSS, Chicago, IL). In ANCOVA analyses, age and whole brain volumes were covariates. Correlation analyses was done by using Spearman's rank test. Statistical significance was defined as $\mathrm{p}<0.05$ by a two-tailed test.

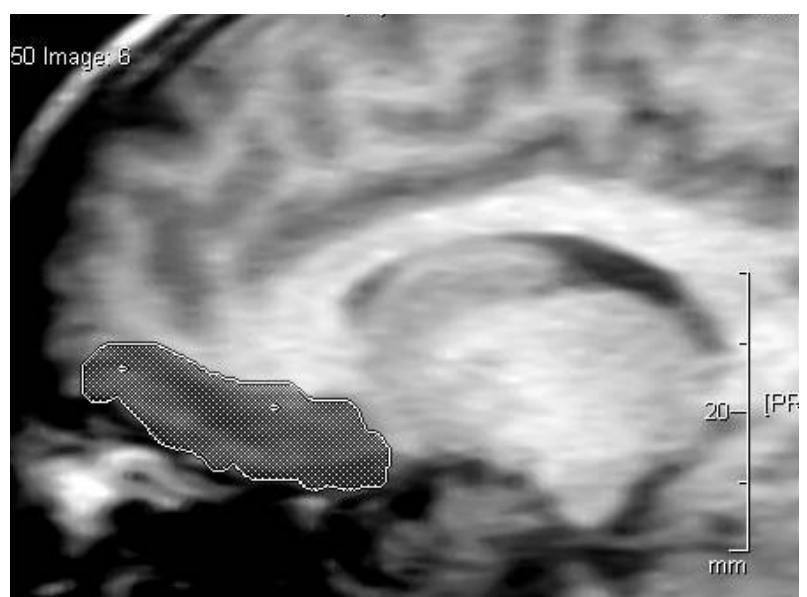

Figure 1. Manual tracing of OFC landmarks. OFC: orbito-frontal cortex.

\section{RESULTS}

The patient and control groups did not differ in regard to demographic and volmetrik variables such as age, gender composition, educational level, and whole brain volume ( $\mathrm{p}>$ 0.05). The PAS scores for the patient group was $15.65 \pm 4.99$. HDRS scores for the patient group and healthy controls were $11.65 \pm 4.68$ and $6.15 \pm 2.43$ respectively $(t=-4.66, p<0.001)$ (Table 1).

As for the total white and gray matter volumes, there were no differences between the patients and healthy controls ( $\mathrm{p}>$ $0.05)$. The patient group had significantly smaller left $(t=-6.70$, $\mathrm{p}<0.001)$ and right $(\mathrm{t}=-5.86, \mathrm{p}<0.001)$ OFC volumes compared to healthy controls. After excluding five patients who had lifetime comorbidity, OFC volumes were still significantly reduced in the patient group compared to healthy controls for both sides $(\mathrm{t}=-6.12, \mathrm{p}<0.001)$ and right $(\mathrm{t}=-5.79, \mathrm{p}<0.001)$.

After ANCOVA analysis with age, gender, and whole brain volume, and HDRS scores as covariates, no significant differences were found between the two groups for the whole brain volume, total white and gray matter volumes $(\mathrm{p}>0.05)$. However, panic patients had significantly smaller volumes of OFC compared to those of healthy control subjects for both left [ANCOVA with age, gender, whole brain volume, and HDRS scores as covariates: $\mathrm{F}=15.32, \mathrm{p}<0.001 ; \mathrm{F}=12.45, \mathrm{p}<0.001$; $\mathrm{F}=15.11 \mathrm{p}<0.001 ; \mathrm{F}=15.10, \mathrm{p}<0.001$, respectively] and right sides [ANCOVA with age, gender, and whole brain volume, and HDRS scores as covariates: $\mathrm{F}=13.01, \mathrm{p}<0.001 ; \mathrm{F}=11.32$, $\mathrm{p}<0.001 ; \mathrm{F}=11.69 \mathrm{p}<0.001 ; \mathrm{F}=27.10, \mathrm{p}<0.001$, respectively]. OFC volumes had not a significant relationship with age both in healthy control subjects $(r=-0.22, \mathrm{p}>0.05)$ and in the pa-

Table 1. Clinical and demographic characterist

\begin{tabular}{|c|c|c|c|}
\hline Item & Patient group $(\mathrm{N}=20)$ & Control group $(\mathrm{N}=20)$ & $\mathrm{p}$ \\
\hline Age (years) & $33.35 \pm 6.51$ & $31.45 \pm 5.71$ & $>0.05$ \\
\hline Gender (female/male) & $12 / 8$ & $11 / 9$ & $>0.05$ \\
\hline Education high school & & & $>0.05$ \\
\hline High school & 5 & 7 & \\
\hline Elemantary school & 6 & 5 & \\
\hline First school & 9 & 8 & \\
\hline Handedness (right) & 20 & 20 & $>0.05$ \\
\hline Length of illness (months) & $0.4 \pm 0.3$ & - & \\
\hline Total PAS score & $15.65 \pm 4.99$ & - & \\
\hline Hamilton depression rating score & $11.65 \pm 4.68$ & $6.15 \pm 2.43$ & \\
\hline Whole brain volume & $1377.51 \pm 230.31$ & $14211.69 \pm 51.03$ & $>0.05$ \\
\hline \multicolumn{4}{|l|}{ OFC volumes } \\
\hline Left & $11.01 \pm 1.55$ & $15.49 \pm 2.42$ & $<0.001$ \\
\hline Right & $10.79 \pm 1.19$ & $14.89 \pm 2.89$ & $<0.001$ \\
\hline
\end{tabular}

PAS: Panic Agoraphobia Scale, OFC: Orbito-frontal cortex 
tients $(\mathrm{r}=-0.19, \mathrm{p}>0.05)$. PAS scores were not correlated with OFC volumes ( $\mathrm{r}=-0.11, \mathrm{p}>0.05)$. Length of illness (mean $\pm \mathrm{SD}=$ $4.1 \pm 3.7$ years), and HDRS scores did not significantly correlate with OFC volumes.

\section{DISCUSSION}

Very limited volumetric investigations were reported regarding OFC in the patients with panic disorder. Recently, Roppongi et al. ${ }^{37}$ focused on the structure of the OFC posterior region, which receives multiple sensory inputs and modulates the anxiety response and investigated differences in the distribution of posterior orbital sulcus (POS) subtypes between patients with panic disorder and healthy control subjects.

It can be said that the present article is one of the first investigations evaluating OFC volumes in the patients with panic disorder. First of all, we would like to emphasize the main findings of this study: For the whole brain volume, total white and gray matter volumes, there were no differences between the patients and healthy controls while the patient group had significantly smaller left and right OFC volumes compared with healthy controls. In the patients with panic disorder, some investigations including whole brain areas using voxelbased morphometry did not reported OFC alterations. One of these investigations, Yoo et al. ${ }^{13}$ reported significantly decreased gray matter volumes of bilateral putamen and reduced at a less conservative level of significance gray matter volumes in the right precuneus, right inferior temporal gyrus, right inferior frontal gyrus, left superior temporal gyrus, and left superior frontal gyrus. The other one ${ }^{14}$ revealed a relatively increased gray matter volume in the midbrain and rostral pons of the brainstem, with increased ventral hippocampal and decreased regional prefrontal cortex volumes at a lower significance threshold. Our finding is similar to results of Roppongi et al. ${ }^{37}$ who found that OFC volumes were smaller in the patients with panic disorder compared to healthy controls and concluded that volume reduction in OFC in panic disorder might be associated with neurodevelopment.

OFC receives direct reciprocal connections from the amygdala ${ }^{19}$ which has been revealed to play an important role in neuroanatomical pathways for panic disorder and so they may be working together to mediate anxiety. It has been demonstrated that OFC mediates anxiety behavior and perception in child and adolescent primates ${ }^{19}$ and is involved in emotional processing ${ }^{20}$ as much the most important clinical aspect of panic disorder, anxiety and fear are associated with the function of the amygdala and fear sensation is stored in the hippocampus itself. Given its association with anxiety modulating role both behaviorally and perceptionally of OFC itself, our finding demonstrating that panic patients had significantly smaller left and right OFC volumes compared with healthy controls may be related to the pathogenesis of panic disorder.

Meanwhile, we did not detect any association between the length of illness and OFC volumes. This led us to consider that OFC volume reduction might be a consequence of neurodevelopmental process, although genetic and/or hormonal factors might be involved in this structural alteration. In this issue, a speculation considering OFC volume reduction over time as a reflection of chronic hypofunction of OFC could be done. Functional imaging of OFC may be useful for revealing this speculation. Moreover, we could not find a relationship between PAS scores and OFC volumes. This finding suggest that smaller OFC volumes do not seem to be associated with illness severity. On the other hand, no comorbidity of agoraphobia in the study subjects may have affected this result.

Some particular limitations in our present findings should be considered. First, our sample size was relatively small. Second, we did not perform a segmentation for OFC volumes. Third, possible selection bias such as the absence of agoraphobia in the patient group and unavailability the PAS of the control group might have affected to results. Fourth, history of pharmacological treatment for comorbid conditions might have affected our results. Fifth, tracing method and the absence of a second blinded investigator for manual tracing were other limitations. Finally, limitations regarding the manual tracing method is another one. The condition that our study did not have the a second blinded investigator for manual tracing might have led to possible selection bias. These are important limitations of our study, and replication with better-controlled samples is necessary to confirm the relevance of our results.

In conclusion, our findings of smaller left and right OFC volumes in the patients with panic disorder indicate changed OFC morphology in the panic disorder and suggest that OFC abnormalities may be involved in its pathophysiology.

\section{REFERENCES}

1. American Psychiatry Association. Diagnostic and Statistical Manual of Mental Disorders, 4th Edition. Washington, DC: APA Press; 1994.

2. Kessler RC, Chiu WT, Demler O, Merikangas KR, Walters EE. Prevalence, Severity, and Comorbidity of 12-Month DSM-IV Disorders in the National Comorbidity Survey Replication. Arch Gen Psychiatry 2005;62:617-627.

3. Fischer H, Andersson JL, Furmark T, Fredrikson M. Brain correlates of an unexpected panic attack: a human positron emission tomographic study. Neurosci Lett 1998;251:137-140.

4. Coplan JD, Lydiard RB. Brain circuits in panic disorder. Biol Psychiatry 1998;44:1264-1276.

5. Pillay SS, Gruber SA, Rogowska J, Simpson N, Yurgelun-Todd DA. fMRI of fearful facial affect recognition in panic disorder: the cingulate gyrus-amygdala connection. J Affect Dis 2006;94:173-181. 
6. Schunck T, Erb G, Mathis A, Gilles C, Namer IJ, Hode Y, et al. Functional magnetic resonance imaging characterization of CCK-4-induced panic attack and subsequent anticipatory anxiety. Neuroimage 2006; 31:1197-1208

7. Gorman M, Kent JM, Sullivan GM, Coplan JD. Neuroanatomical hypothesis of panic disorder, revised. Am J Psychiatry 2000;157:493-505.

8. Fontaine R, Breton G, Dery R, Fontaine S, Elie R. Temporal lobe abnormalities in panic disorder: an MRI study. Biol Psychiatry 1990;27:304310.

9. Vythilingam M, Anderson ER, Goddard A, Woods SW, Staib LH, Charney DS, et al. Temporal lobe volume in panic disorder--a quantitative magnetic resonance imaging study. Psychiatry Res 2000;99:75-82.

10. Massana G, Serra-Grabulosa JM, Salgado-Pineda P, Gasto C, Junque C, Massana J, et al. Parahippocampal gray matter density in panic disorder: a voxel-based morphometric study. Am J Psychiatry 2003;160:566568.

11. Massana G, Serra-Grabulosa JM, Salgado-Pineda P, Gasto C, Junque C, Massana, J, et al. Amygdalar atrophy in panic disorder patients detected by volumetric magnetic resonance imaging. Neuroimage 2003;19:8090.

12. Uchida RR, Del-Ben CM, Santos AC, Araujo D, Crippa JA, Guimaraes FS, et al. Decreased left temporal lobe volume of panic patients measured by magnetic resonance imaging. Braz J Med Biol Res 2003;36: 925-929.

13. Yoo HK, Kim MJ, Kim SJ, Sung YH, Sim ME, Lee YS, et al. Putaminal gray matter volume decrease in panic disorder: an optimized voxelbased morphometry study. Eur J Neurosci 2005;22:2089-2094.

14. Protopopescu X, Pan H, Tuescher O, Cloitre M, Goldstein M, Engelien A, et al. Increased brainstem volume in panic disorder: a voxel-based morphometric study. Neuroreport 2006;17:361-363.

15. Asami T, Yamasue H, Hayano F, Nakamura M, Uehara K, Otsuka T, et al. Sexually dimorphic gray matter volume reduction in patients with panic disorder. Psychiatry Res Neuroimaging 2009;173:128-134.

16. Uchida RR, Del-Ben CM, Busatto GF, Duran FL, Guimarães FS, Crippa JA, et al. Regional gray matter abnormalities in panic disorder: a voxelbased morphometry study. Psychiatry Res 2008;163:21-29.

17. Atmaca M, Yildirim H, Ozdemir H, Tezcan E, Poyraz AK. Volumetric MRI study of key brain regions implicated in obsessive-compulsive disorder. Prog Neuropsychopharmacol Biol Psychiatry 2007;31:46-52.

18. Atmaca M, Yildirim BH, Ozdemir BH, Aydin BA, Tezcan AE, Ozler AS. Volumetric MRI assessment of brain regions in patients with refractory obsessive-compulsive disorder. Prog Neuropsychopharmacol Biol Psychiatry 2006;30:1051-1057.

19. Holland PC, Gallagher M. Amygdala-frontal interactions and reward expectancy. Curr Opin Neurobiol 2004;14:148-155

20. Kalin NH, Shelton SE, Davidson RJ. Role of the primate orbitofrontal cortex in mediating anxious temperament. Biol Psychiatry 2007;62: 1134-1139.

21. Kringelbach ML. The human orbitofrontal cortex: linking reward to hedonic experience. Nat Rev Neurosci 2005;6:691-702.

22. Mellman TA, Uhde TW. Obsessive-compulsive symptoms in panic disorder. Am J Psychiatry 1987;144:1573-1576.

23. Karno M, Golding JM, Sorenson SB, Burnam A. The epidemiology of obsessive-compulsive disorder in five US communities. Arch Gen Psychiatry 1988;45:1094-1099.

24. Austin LS, Lydiard RB, Fossey MD, Zealberg JJ, Laraia MT, Ballenger JC. Panic and phobic disorders in patients with obsessive compulsive disorder. J Clin Psychiatry 1990;51:456-458.

25. Rasmussen SA, Eisen JL. The epidemiology and differential diagnosis of obsessive-compulsive disorder. J Clin Psychiatry 1994;55 (Suppl): 5-10.

26. Fava GA, Zielezny M, Luria E, Canestrari R. Obsessive-compulsive symptoms in agoraphobia: changes with treatment. Psychiatry Res 1988;23:57-63.

27. Hoffart A, Thornes K, Hedley LM, Strand J. DSM-III-R Axis I and II disorders in agoraphobic patients with and without panic disorder. Acta Psychiatr Scand 1994;89:186-191.

28. Perugi G, Akiskal HS, Ramacciotti S, Nassini S, Toni C, Milanfranchi A, et al. Depressive comorbidity of panic, social phobic, and obsessivecompulsive disorders re-examined: is there a bipolar II connection? J Psychiatr Res 1999;33:53-61.

29. Goodwin R, Lipsitz JD, Chapman TF, Mannuzza S, Fyer AJ. Obsessivecompulsive disorder and separation anxiety co-morbidity in early onset panic disorder. Psychol Med 2001;31:1307-1310.

30. Çorapçıŏlu A, Aydemir O, Yıldız M. DSM-IV Eksen I Bozuklukları (SCID-I) İçin Yapılandırılmış Klinik Görüşme, Klinik Versiyon. Ankara: Hekimler Yayın Birliği; 1999.

31. Bandelow B. Assessing the efficacy of treatment for panic disorder and agoraphobia. II. The Panic and Agoraphobia Scale. Int Clin Psychopharmacol 1995;10:73-81.

32. Hamilton M. Development of a rating scale for primary depressive illness. Br J Soc Clin Psychol 1967;6:278-296.

33. Yuh WTC, Tali ET, Afifi AK, Sahinoglu K, Gai F, Bergman RA. MRI of Head \& Neck Anatomy. New York: Churchill Livingstone; 1994.

34. Jackson GD, Duncan JS. MRI Anatomy: A New Angle on the Brain. New York: Churchill Livingstone; 1996.

35. Patel VH, Friedman L. MRI of the Brain: Normal Anatomy and Normal Variants. Philadelphia: WB Saunders Company; 1997.

36. Riffkin J, Yucel M, Maruff P, Wood SJ, Soulsby B, Olver J, et al. A manual and automated MRI study of anterior cingulate and orbito-frontal cortices, and caudate nucleus in obsessive-compulsive disorder: comparison with healthy controls and patients with schizophrenia. Psychiatry Res 2005;138:99-113

37. Roppongi T, Nakamura M, Asami T, Hayano F, Otsuka T, Uehara K, et al. Posterior orbitofrontal sulcogyral pattern associated with orbitofrontal cortex volume reduction and anxiety trait in panic disorder. Psychiatry Clin Neurosci 2010;64:318-326. 